\title{
Introduction of the EURO: Implications for Swiss Tourism?
}

By Thomas Bieger \& Christian Laesser

\section{CONTENTS}

1 Introduction 2

2 New challenges and advantages by a Single Currency Market 3

2.1 General aspects for enterprises in Europe 3

2.2 Specific aspects for tourism 3

3 Consequences and perspectives for tourism in Switzerland 4

3.1 Price transparency 4

3.2 Marketing in times of the EUR

3.3 Operational implications for the touristic enterprise 5

\section{EUR vs CHF:}

The exchange rate as a crucial success-factor for Swiss Tourism 6

4.1 General conditions $\quad 6$

$\begin{array}{ll}4.2 \text { Sensitivity of demand } & 7\end{array}$

5 Conclusions $\quad 10$

6 Sources $\quad 12$

\section{TABLES}

Table 1: $\quad$ Shares of overnight stays in Switzerland 2

$\begin{array}{ll}\text { Table 2: } & \text { Exchange-rate-elasticity of overnight stays of selected countries in } \\ & \text { Switzerland (in\%) }\end{array}$

Table 3: $\quad$ Price Elasticity of overnight stays of selected countries (in\%) 8

Table 4: $\quad$ Estimation of Impacts of the EUR on touristic companies in general 9

Table 5: $\quad$ Estimation of Impacts of the EUR on touristic branches in particular 9

Table 6: $\quad$ Strategic options of swiss tourism enterprises 10 


\section{Introduction}

With the introduction of the EUR, a new time of European economy and tourism has begun: Also for Switzerland and its tourism, times have changed by the $1^{\text {st }}$ January 1999.

Mainly due to a small domestic market (only 7 Mio. consumers), the entire swiss economy in general has always been dependent on international trade. Particularly tourism in that country contributes $8 \%$ to all swiss exports (and about $5.6 \%$ to the GNP). (STV 1998). Like the rest of the economy, it is narrowly hocked to the European Union and the single currency area: about $1 / 3$ of all overnight stays are generated in EUR; combined with the domestic market $(\mathrm{CHF})$ it adds to $2 / 3$ (see Table 1 ).

\section{Table 1:}

Shares of overnight stays in Switzerland
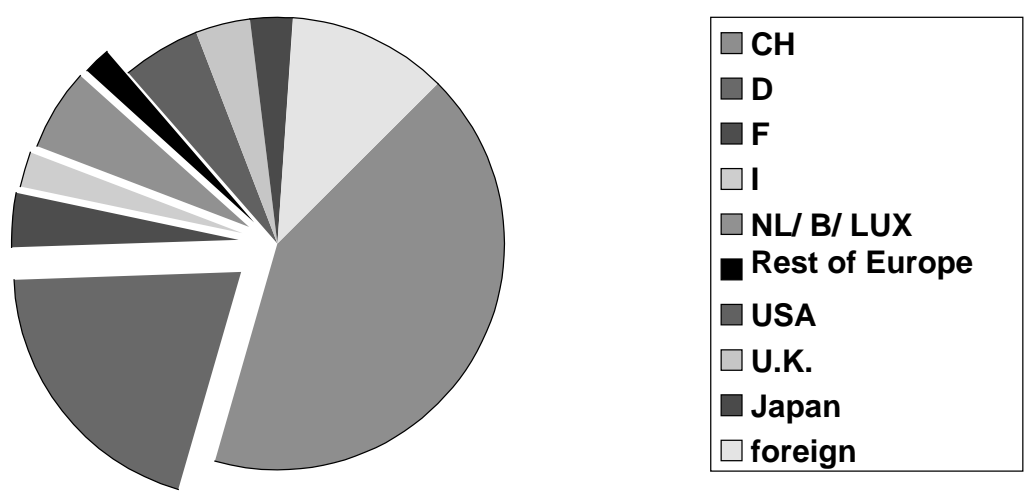

Source: $\quad$ STV (1998)

That new situation leads to a major change in the general competitive conditions of tourism in Switzerland. Therefore, this article

- outlines the changes for enterprises in general and tourism in particular.

- secondly will discuss the consequences and perspectives for swiss tourism companies

- third, will focus on the development of exchange rates. This point is one of the most crucial ones in the relations between Switzerland and Europe. Research has shown, that the demand for swiss tourism services is significantly dependent on the development of exchange rates between the CHF and the major European currencies (JÄGER 1996). With the exchange rate being similar and not influencable for $1 / 3$ of the market and tourism being a price-sensible business, swiss tourism professionals have to cope with a complex situation. 


\section{New challenges and advantages by a Single Currency Market}

\subsection{General aspects for enterprises in Europe}

The introduction of the EUR fundamentally boosts the single market perspective. Enterprises in general will (among other things) (KOMMISSION 1997¹, BECKERS 1997, DIHT 1997):

- save on exchange commissions and transaction costs;

- benefit from improved price stability and most probably lower cost of capital, because the risk premium on loans may be lowered;

- experience the advantages and disadvantages of a significantly more transparent market;

- have the opportunity to pay more attention to distances and market potential than to country borders;

- benefit from the elimination of relative price distortions caused by misaligned exchange rates.

The competitive environment is changed deeply by several means (BECKERS 1997):

Past

- tariffication by country

- parallel imports in several industries

- disparity in prices across Europe

- national markets of limited potential

\section{Future}

- price transparency

- pan-european pricing

- decrease in the average price level/ plant relocation/ squeeze in supplier margins

- large domestic market

Besides of the above mentioned, pan-european accounting standards and corporate tax harmonisation can be expected (ESM priority).

\subsection{Specific aspects for tourism}

As for tourism, the aspect of price transparency is one key issue. "Tourism is expected to mainly benefit from a single european currency. The switch to a single currency in many nations of the EU will have a positive impact on tourism by making prices even more transparent and increasing competition." (WTO, 1998). Tourism has been already one of the most transparent market in the world, mainly because electronic distribution has enabled the customer to compare prices and offers a long time before he could do so with other products and services (LAESSER $1998^{2}$ ). The comparison will be even easier through the introduction of one common currency; therefore transparency will be even faster and deeper than in other industries.

That increased price transparancy will lead to more market-prices and to an increased price stability. One possible trategy of the industry to reduce transparency could lead to the tendency to artificial intransparency by an extension of packages (by tour operators and/ or incoming agencies) to make them more complex to be valuated by the customer. The benefit 
for the guest and the reason of his increased willingness to pay could be found in the improved convenience of such products and a reduced insecurity in regard to the total cost of travel (LAESSER 1998 ${ }^{2}$ ). The experienced traveller though is expected to benefit from the advantage of increased transparency by becoming even more price-sensitive.

The increasing role of distances instead of national borders is another fact to become important. Especially for overseas guests, the single currency boosts a rather homogenous view of Europe. Only differences in languages will on the long run remain as key national distinction marks. Therefore, Europe will more and more be looked at as one product. Because of that, tourism marketing will need a reallocation of means and budgets: For efficiency reasons and to guarantee a critical mass, a shift from local to destination level has to be taken into account even more. Furthermore, since countries will loose importance as a differentation quality for tourism products, a shift from the national to destination and European level will become necessary. The positioning of (well-known) regional destinations will become easier, mainly because they do not necessarily have to refer to their national classification (example: the Baleares belong rather to Europe than to Spain).

\section{Consequences and perspectives for tourism in Switzerland}

For tourism in Switzerland, there is a number of consequences to be observed when dealing with the EUR.

\subsection{Price transparency}

Touristic enterprises in Switzerland will have to accept the EUR as a regular means of payment, mainly to assure today's necessary convenience of touristic products (BIEGER 1998) and to be therefore competitive on the European market. There is an additional perspective which has to be taken into account: Overseas guests travelling in Europe will want to be able to use one currency (convenience!). The acceptance of the EUR as a means of payment also implies to tender in EUR. With that measure, Switzerland lands itself in the row of all European countries. For the guest (no matter from Europe or from overseas) on the long run there will be one "leisure"-currency in Europe (first using credit cards, later in the form of bills and coins).

In addition, a number of pricing-practices will become obsolete, because swiss tourism too has to reorientate itself rather on distances and market potential than on national markets. Among those measures is the widely practiced price-discrimination by national boundaries. Pricing by motive-groups or on the base of different customers different willingness to pay is becoming more important.

Up to now, national price setting is also determined by national tariffs and price-settings for tourism (especially wages; in the EUR-area as in Switzerland). A single currency can - on the long term - only be succesful under the condition of a harmonisation in taxation and social security (BECKERS 1997, DIDZOLEIT 1998, KOMMISSION 1997²), those national orientated tariffs will eventually disappear. For a country not participating in the EUR area but 
being dependent on economic relations with that same area, action has to be taken towards the creation of either a very competitive social security or at least a minimal harmonisation with the above mentioned major determining factors.

On the other hand, Switzerland as the only country in central Europe with an own local currency could gain interest and awareness in specific segments on international markets due to its image and the character of its tourism industry.

\subsection{Marketing in times of the EUR}

The work with a bi-currency system (as it may turn out in Switzerland) opens new changes and possibilities in EUR related marketing.

First of all, the price transparency in Europe will contribute to a re-evaluation of Switzerland's price image in Europe and the rest of the world (ZAUGG 1998). It is no secret that in the past years prices for touristic products and services have become stable or, in certain cases, have even declined. The price-image of Switzerland is - in major parts of the markets -opposite of the facts. Therefore, the possibility of tendering and selling touristic products and services in EUR will open a chance to correct the rather negative price image of Switzerland. This strategic goal will have to be included in the marketing conceptions of the near future.

Due to the bi-currency system, efficient means of payment have to be installed. One of it lies in the consistent acceptance of cashless transactions, either by credit card or by cash card. Credit cards are accepted in the whole country by the overwhelming part of the tourism industry and to a larger proportion than for example in Austria. With the acceptance of cashless payments, convenience towards the customer can be significantly increased. Therefore, the EUR could be a nice booster in Switzerland to even more companies accepting credit cards, a fact also to be included in the marketing of the future.

For a tourism company, the decision whether to adopt a fixed exchange rate between $\mathrm{CHF}$ and EUR will be of major strategic importance. By working with a fixed exchange rate, the risks of changing currency-exchange-rates will be transferred entirely to the company, since customers will expect an improvment of exchange rates (strong EUR) to be transmitted to the prices - otherwise he will have the opportunity to pay in swiss Francs. On the other hand, the consequences of a weaker EUR will have to be carried out by the tourism company.

\subsection{Operational implications for the touristic enterprise}

The rethinking of marketing is definitely one of the most important measures touristic enterprises have to take. But this orientation has consequences in a number of operational functions. Among those are (DIHT 1997, KOMMISSION 1997') :

- Sourcing (mainly international)

- Electronic data processing / informatics

- Finances

- Contracting 
- Management of personal

- Financial transactions

to name just a few of them.

One can assume that in the future more or less each touristic enterprise in Switzerland will also have incomes in EUR. On the other hand, there are two possibilities of spending EUR without having to exchange them into the still main currency in Switzerland, the CHF. It is the sourcing of goods and personal in the EUR area which opens the possibility of working with two currencies. While the sourcing of goods does not cause any major problems (perhaps with the exception of agricultural products), the paying of European personal in EUR will be difficult due to legal objections. Among those are the transactions when dealing with swiss social security (which have to be in CHF). On the other hand, the swiss labor wages rely very much on freedom of treaty so that a compensation system linked to economic development and exchange-rate-developments are not completely unthinkable. Therefore, it is not sure yet if European personal in swiss tourism enterprises are going to be paid in $\mathrm{CHF}$ only or if there will be a bi-currency system installed. For swiss tourism, being highly dependent on the European personal, that is not a very encouraging perspective, especially since Switzerland enjoys a high level of wages and prices.

Finance-Management is another different task. Indisputably, the biggest challenges result from the fact of having to operate a two currency systems. Besides of having to deal with technical problems when encashing different currencies, touristic enterprises in Switzerland face the need of professional currency-exchange management. The major task hereby is to ease the risk and implications of currency exchange rates. This can be done:

- by professional exchange observation and analyses;

- by securing exchange rates by options and futures;

- by professional currency management with the goal of using incoming EURs for EUR contracts

No matter what, the future exchange rates between the CHF and the EUR will be crucial for the development of tourism in Switzerland. Therefore, one has to put some attention into the analyses of the future development of the EUR.

\section{EUR vs CHF: \\ The exchange rate as a crucial success-factor for Swiss Tourism}

\subsection{General conditions}

In Switzerland, the discussion about the relation between the CHF and the EUR has been dominated for a long time by the fear of the swiss managers from a too strong CHF. This rather emotional analysis has to be complimented by some "rational" remarks. The condi- 
tions for the EUR to become a strong currency are all more or less fulfilled. The EUR will be an important international currency, if (BECKERS 1997):

- it stands as a representative for an important economic region;

- it refers to an area with considerable economic autonomy;

- it is accepted as an international invoicing currency;

- it is accepted as an international investment currency

- it is accepted as an international reserve currency;

Trade of the first two months of 1999 has shown that the EUR, at least towards the CHF, seems to be a rather stable and strong currency. The future of that relationship is still unknown, though. Several reasons still would lead to a weak EUR (NZZ 113/98), others (especially the stability treaty and its credibility) to a strong one (DURRER 1998).

On the short run (next two years) there is no major threat to be expected towards destabilising the EUR, mainly because it will be not before 2001 that possible sanctions towards countries violating the stability treaty would become effective. When looking into the past, long-term interest rates have converged towards comparibly low $5.25 \%$, which is another good indicator for ongoing stability.

In the future, the Swiss National Bank will be the only one willing to influence the currency exchange rate between the CHF and the EUR, mainly because it is not one of the European Central Bank's premier goal to steer that exchange rate. With the current inflation outlook in Switzerland, the Swiss National Bank can be expected to rather lower interest and take other measures to stabilise the EUR on the level of $1.60 \mathrm{CHF}$.

For all those reasons, one can expect a rather stable exchange rate betwen CHF and EUR, which leads to the options earlier described. In the end, one might ask if, on a daily base, the EUR was going to replace the CHF. It is quite possible, that the EUR is able to install itself as a major currency for transactions in Switzerland. But mainly because of legal objections (a CHF based social security system), the personal intensive character of services prevents the CHF to be entirely replaced by the EUR in tourism.

\subsection{Sensitivity of demand}

Tourism in Switzerland is as price-sensitive as in other countries. Exchange rates aditionally influence prices in international tourism. In the EUR-area, that influence is now parishing; prices will come straight to the customer, without the „shield“ of a currency exchange rate.

Changing exchange rates will still lead to price changes of swiss touristic products in other countries and in Europe. Therefore, exchange rate elasticity is of major importance for swiss tourism companies. Significant differences can be found between different country markets. Reasons for those differences are such as the average income level or the different forms of tourism, resulting from different cultures/ traditions. Furthermore, emotional ties to a destination and different exchange rates of competing destinations outside the EURarea contribute to those differences (JÄGER 1996). 
The analysis of the past (1980-1993) sensitivity regarding the currency-exchange-rate (see Table 2) shows especially dutch and belgian people reacting relatively sensitive. A 1\%increase in the cost of the CHF implies overnight stays in hotels are being reduced by more than $2.5 \%(\mathrm{NL})$ and $1.5 \%(\mathrm{~B})$.

\section{Table 2:}

\section{Exchange-rate-elasticity of overnight stays} of selected countries in Switzerland(in\%)

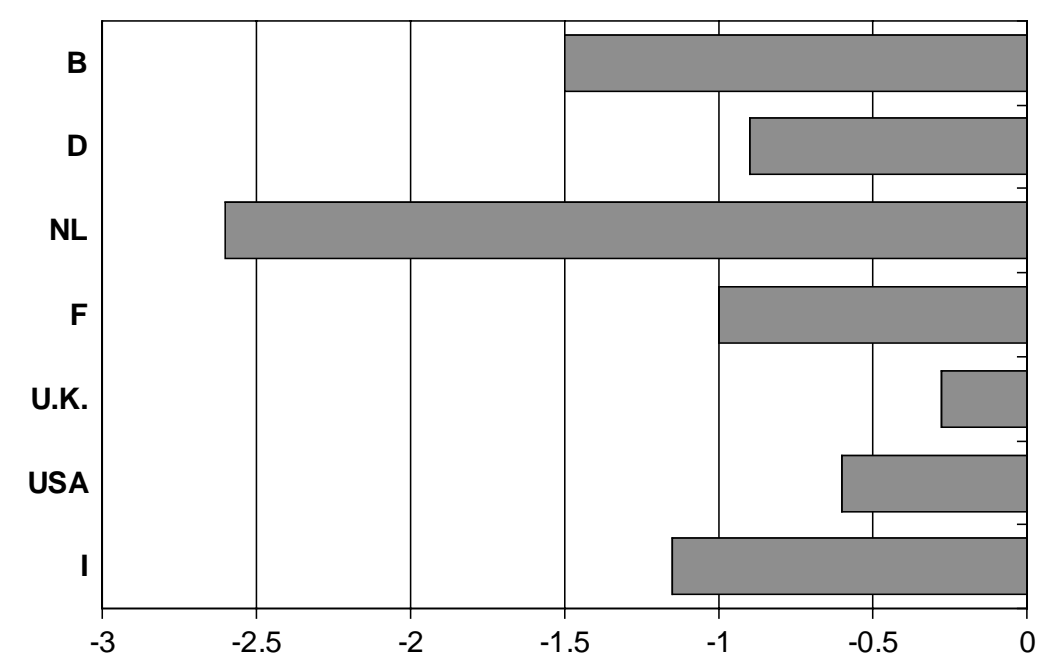

Source: JÄGER (1996); base: 1980-1993

Looking at the reaction on the relative change of prices (from the point of view of the origin countries) of swiss touristic products, one can observe a similar pattern (see Table 3). That later analysis of SCHIPS confirms the earlier results of JÄGER in the study discussed before.

Table 3:

Price Elasticity of overnight stays of selected countries (in\%)

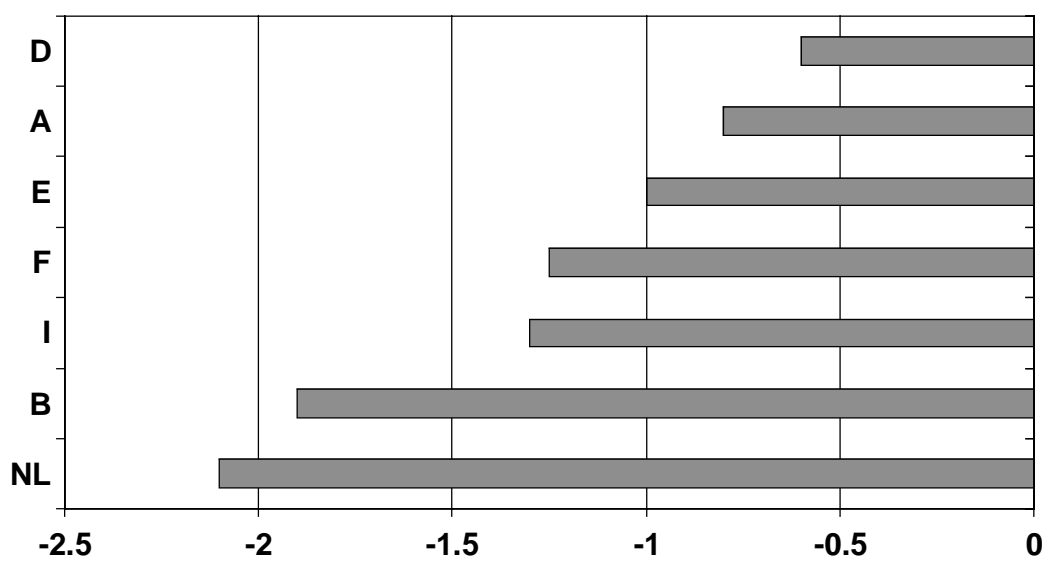

Source: $\quad$ SCHIPS (1998)

The incertainity on the development of the exchange rate between the EUR and the CHF combined with the impact of a possible weak EUR results in a rather sceptic-positive attitude of tourism professionals towards "Europe" in general and the EUR in particular 
(BIEGER/ LAESSER 1999). A recent survey - consisting of 127 written company interviews in the canton of Berne - has shown that about $30 \%$ of all tourism companies consider the EUR as very or rather problematic, while only about $20 \%$ expect very positive impacts on their company (see Table 4). Larger companies (company turnover $>$ median) evaluate the EUR in a scale of 1 (very problematic) to 4 (very positive) rather positive (3.05); smaller companies (company turnover < median) on the other hand are more reluctant (2.65). Under the categorization of the turnovers by its quartiles, the above mentioned difference is significant on a 95\%-level (BIEGER/ LAESSER 1999). That fact could be based on the degree of potential professionalism to deal with a complex problem such as a bi-currency system.

Table 4:

Estimation of Impacts of the EUR on touristic companies in general

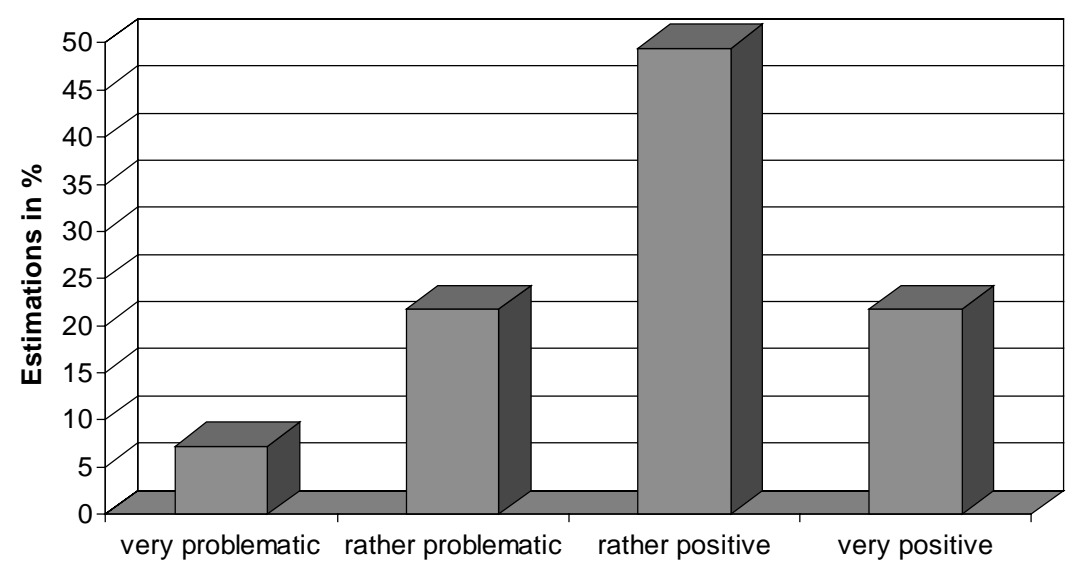

Source: BIEGER/ LAESSER (1999)

Table 5:

Estimation of Impacts of the EUR on touristic branches in particular

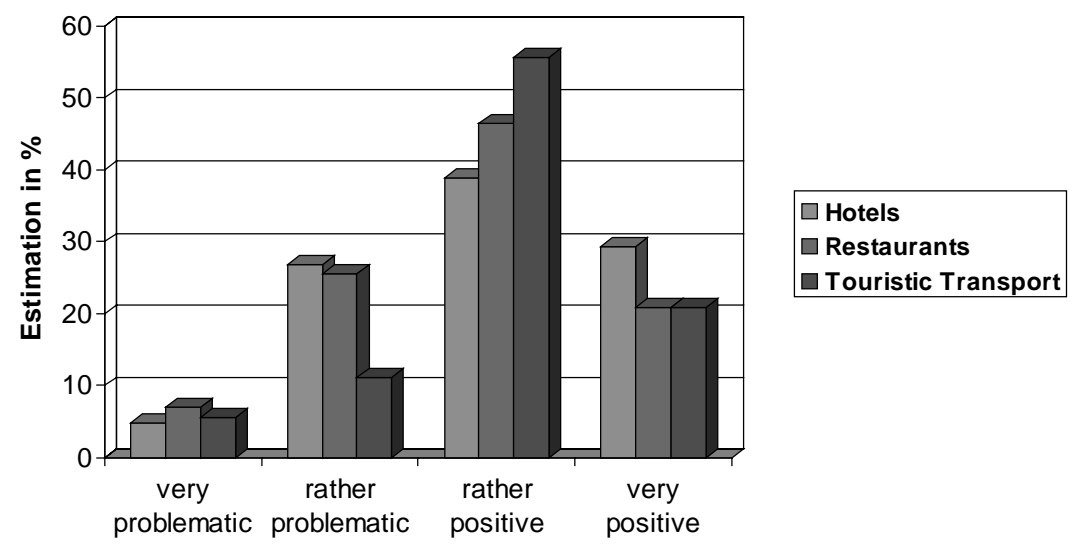

Source: BIEGER/LAESSER (1999)

The analysis shows further (see Table 5) the different estimation by major branches. Hotels show a rather ambivalent estimation, while transport companies are clearly in favour of the 
EUR. That result can be explained by the degree of directness of impacts by the EUR: Hotels in general are in closer touch to foreign guests than transport companies.

llast but not least, the same survey has shown that in comparison to other possible challenges (short-term travel decisions, competitiveness in the international sightseeing-tourism, the demand for time/ cost-efficiency regarding touristic products), the introduction of the EUR is the currently most remarkable one (LAESSER/ BIEGER 1999).

\section{$5 \quad$ Conclusions}

Drawn from the arguments of the above sections, the introduction of the EUR will lead to the following strategic choices for tourism enterprises in Switzerland (see Table 6):

- Whether to use EUR as a means of payment: As mentioned above, all companies competing on European or transcontinental sightseeing-markets will be forced to give the possibility to pay in EUR or to pay with credit cards.

- Whether to adopt a guaranteed exchange rate: This decision depends mainly on the importance of the international market for the specific enterprise and its ability to differentiate itself in products and therefore to succeed having a relative monopoly position.

Table 6:

Strategic options of swiss tourism enterprises

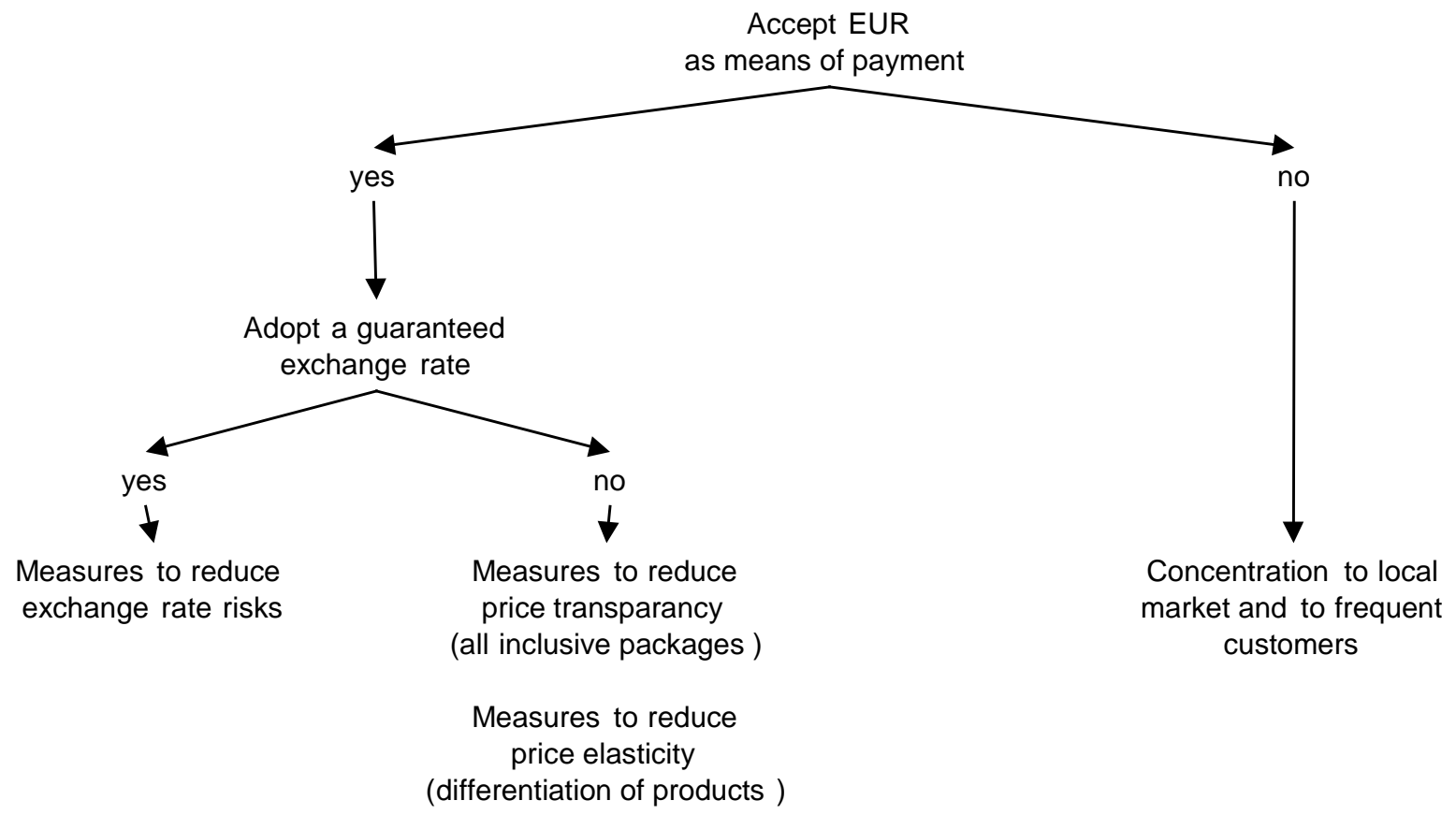

Overall, swiss tourism can face the EUR in an active or rather passiv manner. An active strategy would lead to measures like

- positioning a country with excellent proce-value position (fight the "expensive" image);

- promoting the country as "unique" and "original";

- follow an effective differentiation strategy for all products. 
A passive strategy mainly consists of measures for the reduction of exchange rate risks through

- adopting financial market instruments;

- payments as much as possible in EUR;

both on a cooperative level to reduce transaction costs.

At the end, a combination of both strategic approaches can be expected. 


\section{Sources}

BECKERS, L. (1997): EMU-Facts and EMU-Preperation, Bruxelles

BIEGER, TH. (1998): Dienstleistungsmanagement, Bern/ Stuttgart/ Wien

BIEGER/ LAESSER (1998): Neue strukturen im Tourismus - Der Weg der Schweiz, Bern/ Stuttgart/ Wien

BIEGER/ LAESSER (1999): Rahmenbedingungen des Tourismus im Kt. Bern, Bern (noch unveröffentlichte Untersuchung im Auftrag des Handels- und Industrievereins Bern)

Didzoleit, W. (1998): Kohls Alptraum - Wenn der Euro aber doch schwach wird, in: Spiegel Spezial 2/1998, S. 54-58

DIHT (1997): Euro im Tourismus - Fakten, Fragen, Empfehlungen -, Bonn

DURRER, K. (1998): Euro-Chance und Herausforderung für die Schweizer Wirtschaft, in: UBS Outlook Schweiz 1/98

JÄGER, F. (1996): Auswirkungen von Wechselkursschwankungen auf den Schweizer Tourismus, in: KASPAR, C. (Hrsg): Jahrbuch der Schweizerischen Tourismuswirtschaft 1995/96, St. Gallen

KOMmISsION (1997¹): Praktische Aspekte der Einfürhung des Euro, texte zum Euro Nr.8, Bruxelles

KOMMISSION (1997²): Auswirkungen der Umstellung auf den Euro auf Politik, Institutionen und recht der Gesellschaft, Bruxelles

LAESSER, CH. (1998): Strategische Optionen der Schweizer Tourismuswirtschaft in der europäischen Währungsunion, Referatsunterlage an den Landecker Europatagen, Landeck

LAESSER, CH. $\left(1998^{2}\right)$ : Destinationsmarketing im Zeitalter des Internets, Bern/ Stuttgart/ Wien

SCHIPS, B. (1998): Was bedeutet der Euro für den Schweizer Tourismus, Zürich

STV (1998): Tourismus in Zahlen, Bern

WTO (1998): Tourism to benefit from single europan currency, Madrid

ZAUGG, B. (1998): Der Euro und die Schweizer Hotellerie - ein Zwischenbericht, Bern 